\title{
¿Pitiriasis rosada o COVID?
}

\author{
Pityriasis rosea or COVID?
}

\author{
María Graciela Guzmán Perera, * Patricia Alfaro Ledesma, * \\ Mavi Patricia López Sroor, ${ }^{\ddagger}$ Marcela Saeb Lima ${ }^{\S}$
}

Citar como: Guzmán PMG, Alfaro LP, López SMP, Saeb LM. ¿Pitiriasis rosada o COVID? Acta Med Grupo Angeles. 2021; 19 (s1): s64-s68. https://dx.doi.org/10.35366/101030

\section{Resumen}

La pitiriasis rosada es una enfermedad dermatológica causada por herpes virus 6-7 (HHV), se presenta habitualmente durante el invierno y principio de la primavera. Durante la pandemia por virus SARS-CoV-2 su incidencia ha aumentado hasta cinco veces en las clínicas dermatológicas y consultorios fuera de hospitales. También ha habido casos asociados a la enfermedad COVID-19, pudiéndose presentar previo a los síntomas, junto con ellos y en forma tardía. Los efectos hematológicos del virus SARS-CoV-2, sobre todo la linfopenia, podrían tener un factor fisiopatogénico en la activación del virus.

Palabras clave: Placa, pápulas, escama, herpes virus, Epstein-Barr virus, exantema.

\section{INTRODUCCIÓN}

Durante la pandemia por SARS-CoV-2 se han descrito diversos cuadros clínicos. Los exantemas que se han observado tienen diversa morfología. ${ }^{1}$ La pitiriasis rosada de Gibert es una dermatosis muy particular, durante mucho tiempo se sospechó el origen viral y recientemente se asoció con los herpes virus 6 y $7 .^{2}$ La enfermedad es muy enigmática, en general no da síntomas sistémicos, no conocemos su modo de transmisión ni tampoco por qué aparece durante el final del invierno y principio de la primavera. En el curso de la pandemia hemos observado que varias series de pacientes han reportado casos de dermatosis muy similares asociadas a la infección por SARS-CoV-2. ${ }^{1-5}$ Pueden aparecer antes de los síntomas, durante la enfermedad o en forma tardía

\section{Abstract}

Pityriasis rosea is a dermatological disease caused by herpes virus 6-7 (HHV), it usually occurs during winter and early spring. During the SARS-Cov2 virus pandemic, its incidence has increased up to 5 times in dermatological clinics and outof-hospital clinics. There have also been cases associated with the COVID-19 disease, being able to present before the symptoms, together with them and later. The hematological effects of the SARS-Cov2 virus, especially lymphopenia, could have a physiopathogenic factor in the activation of viruses.

Keywords: Plaque, papules, scale, herpes virus, EpsteinBarr virus, exanthema.

como muchos otros exantemas. Hay un caso reportado en el que la nueva virosis detonó una reinfección endógena por virus Epstein Barr y Herpes. ${ }^{6}$ Presentamos los casos vistos de cuadros similares y atípicos que ha habido, algunos con PCR + , otros que fueron positivos al marcaje inmunohistoquímico con SARS-CoV-2 y algunos en los que no pudimos encontrar evidencia de contacto con el nuevo virus.

\section{CASOS CLÍNICOS}

\section{Caso 1}

Paciente femenino de 46 años de edad, apendicectomía hace 30 años, antecedente de mamoplastia y abdomi-
* Dermatóloga del Hospital Ángeles Pedregal.

* Dermatóloga del Hospital Ángeles Chihuahua.

$\S$ Dermatóloga y Dermatopatóloga del INCMNSZ, Centro Médico ABC y Hospital Ângeles Lomas.
Correspondencia:

María Graciela Guzmán Perera

Correo electrónico: graceguzman07@gmail.com

www.medigraphic.com/actamedica 

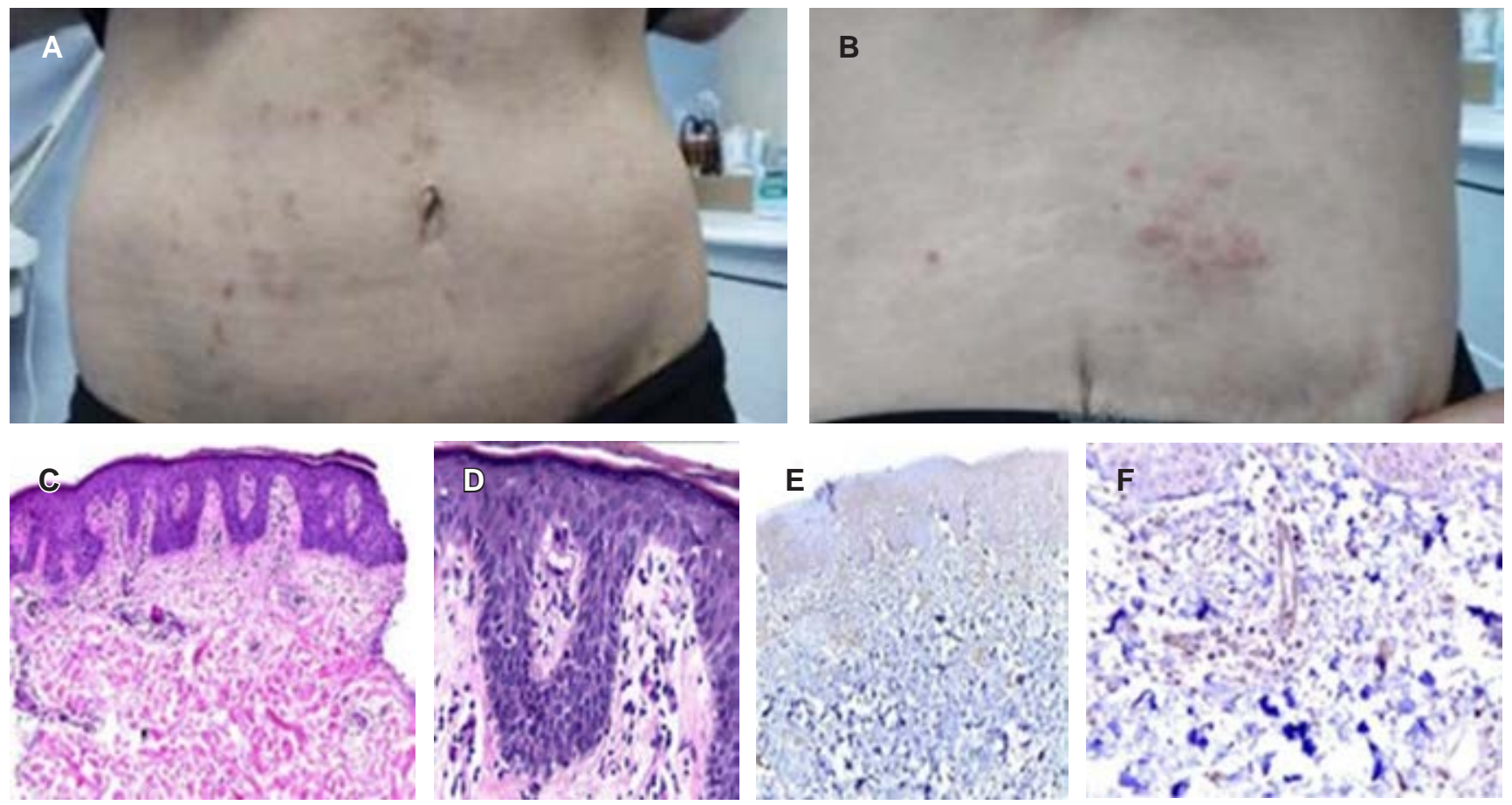

Figura 1: A y B) Erupción maculopapular con placas redondeadas y ovales descamativas. C y D) Biopsia de piel: Biopsia de piel panorámica y acercamiento. Epidermis con acantosis irregular. Degenración vacuolar de la capa basal con exocitosis de linfocitos e infiltrado inflamatorio perivascular por linfocitos y neutrófilos. E y F) Inmunohistoquímica positiva para proteína Spike.

Figura 2:

A) Dermatosis de aparición súbita con lesiones en placas ovales y papulares que afectan el tórax, axilas y brazos. Sin prurito, de 12 horas de evolución.

Sin síntomas generales o respiratorios. B-D) Biopsia de epidermis con paraqueratosis en red de canasta, presencia de microabscesos de neutrófilos de interfaz vacuolar focal con espongiosis. Infiltrado inflamatorio perivascular por linfocitos y neutrófilos. Extravasación de eritrocitos.
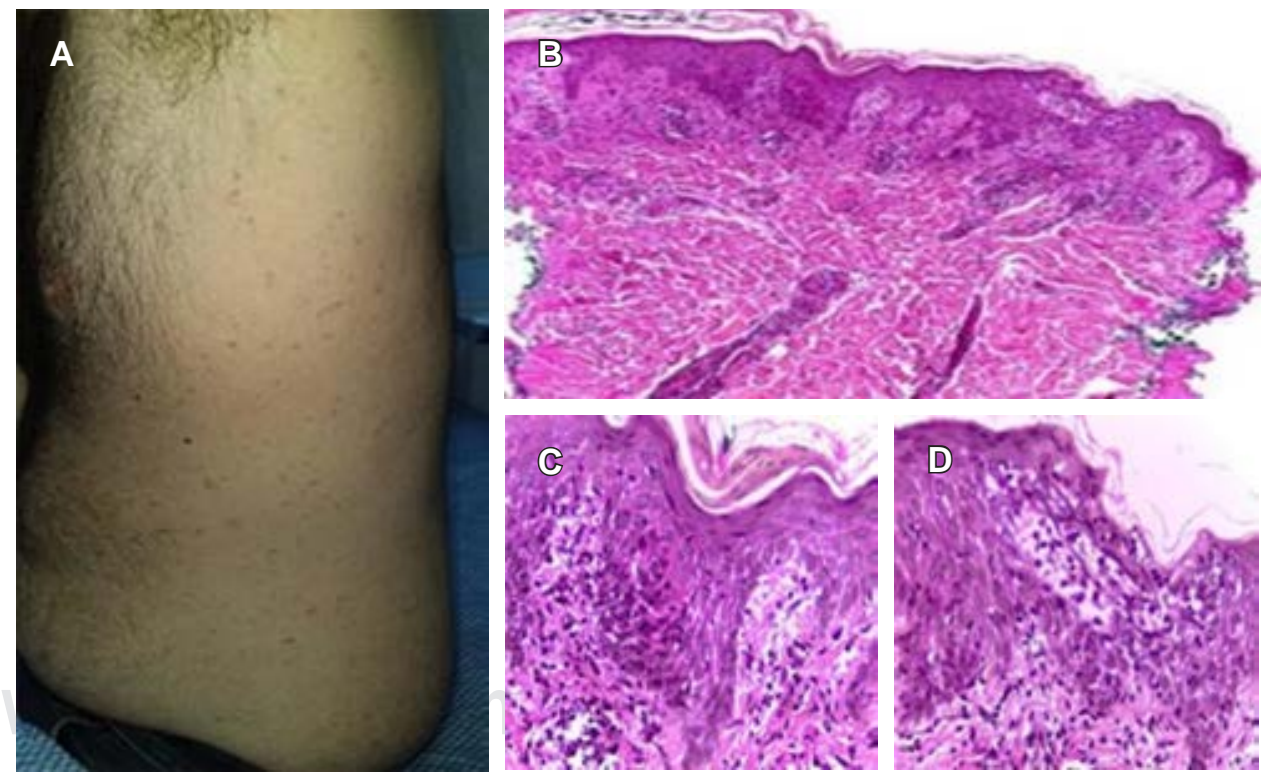

noplastia. Consulta en julio de 2020 con una dermatosis de 36 horas de evolución caracterizada por una placa eritematoescamosa en el abdomen, con escama fina en los bordes y pequeños elementos ovales y descamativos que afectaban el abdomen, sin prurito, la paciente sólo tomaba vitaminas. PCR negativa. Elevación de $\lg G$ a las tres semanas. Tratamiento: sustitutos de jabón, esteroides tópicos, lubricantes. betametasona/loratadina, ivermectina cuatro tabletas $6 \mathrm{mg}$ y nitazoxanida seis días.

La dermatosis resolvió en cinco días (Figura 1). 


\section{Caso 2}

Masculino de 27 años de edad. Sin antecedentes personales de importancia o enfermedades crónicas. Negó ingesta de algún tipo de medicamento. Consulta el 10 junio por dermatosis de 36 horas de evolución que afectaba el tronco anterior y posterior, raíz de las extremidades superiores, compuesto de placas de 4-5 mm las de diámetro mayor y de $3 \mathrm{~mm}$ las de diámetro menor, ligeramente descamativas. Asintomáticas de aparición súbita sin haber presentado placa heraldo. Negó haber salido del confinamiento desde el mes de abril salvo para actividades muy necesarias y contacto sexual no protegido en los últimos dos meses.

Se sospechó pitiriasis rosada atípica asociada con COVID-19. PCR negativo, biometría hemática, química sanguínea, marcadores de inflamación y VDRL negativos.

Se trató con sustitutos de jabón, glucocorticoides tópicos, ivermectina $6 \mathrm{mg}$ cuatro dosis, nitazoxanida 500 mg uno diario por seis días. Resolvió en seis días sin dejar secuelas (Figura 2).

\section{Caso 3}

Masculino de 36 años, originario y residente de Chihuahua, sano en general y no requería medicamentos. Consultó en julio de 2020 por una dermatosis de ocho días de evolución que inició con una placa eritematoescamosa de aproximadamente $4 \mathrm{~cm}$ de diámetro en tórax, asintomática y posteriormente aparición de pequeños elementos distribuidos en "árbol de Navidad", además tenía lesiones ovales "en medallón" que afectaban ambas regiones inguinales. Mostraba astenia moderada, sin fiebre o síntomas respiratorios. Se diagnosticó como pitiriasis rosada, se manejó con valaciclovir por 10 días sin respuesta, lubricantes y glucocorticoides tópicos, la dermatosis persistió 17 semanas y desapareció en forma espontánea (Figura 3).

\section{Caso 4}

Femenino de 23 años de edad, originaria de Ciudad Juárez que teleconsulta en marzo de 2020 por una dermatosis de ocho días de evolución, diseminada, que afectaba el tronco y las áreas proximales de los miembros superiores, con pápulas y placas eritematoescamosas distribuidas en "árbol de Navidad" y sospecha de haber tenido una placa "heraldo" una semana antes del brote agudo. Se diagnosticó pitiriasis rosada, pero se efectuó PCR para SARS$\mathrm{CoV}-2$ que resultó negativo. El tratamiento con valaciclovir

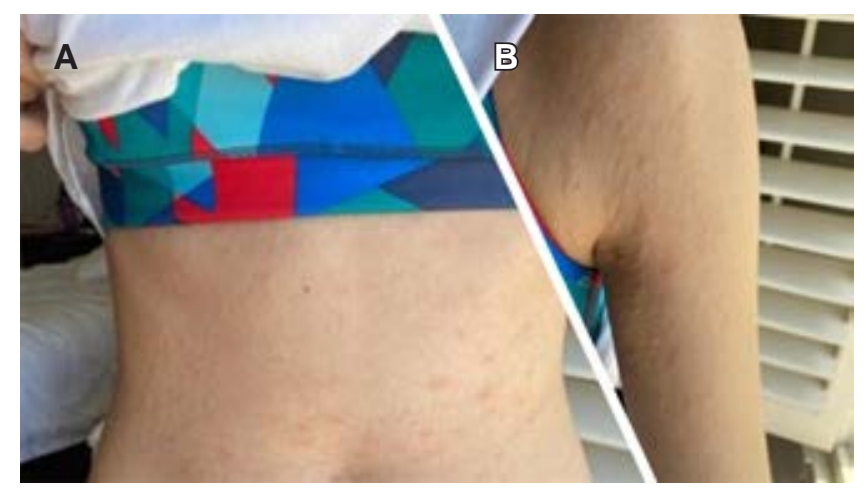

Figura 4: A y B) Dermatosis diseminada que afectaba el tronco anterior y posterior y la parte proximal de las extremidades superiores e inferiores. Consta de un exantema maculopapular con placas ovales descamativas dispuestas en "árbol de Navidad" e historia de "placa heraldo" días antes.
Figura 3:

A y B) Exantema maculopapular, placas redondeadas descamativas con centro más claro que afectan el tórax en toda su extensión.
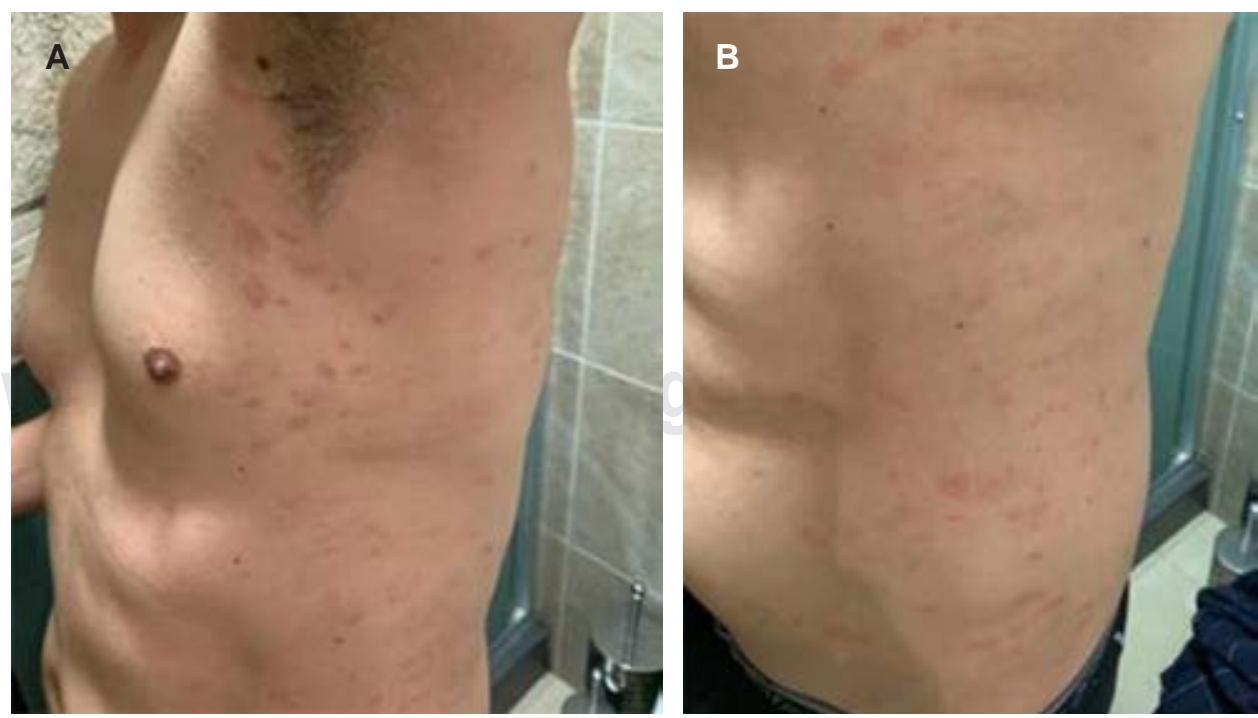


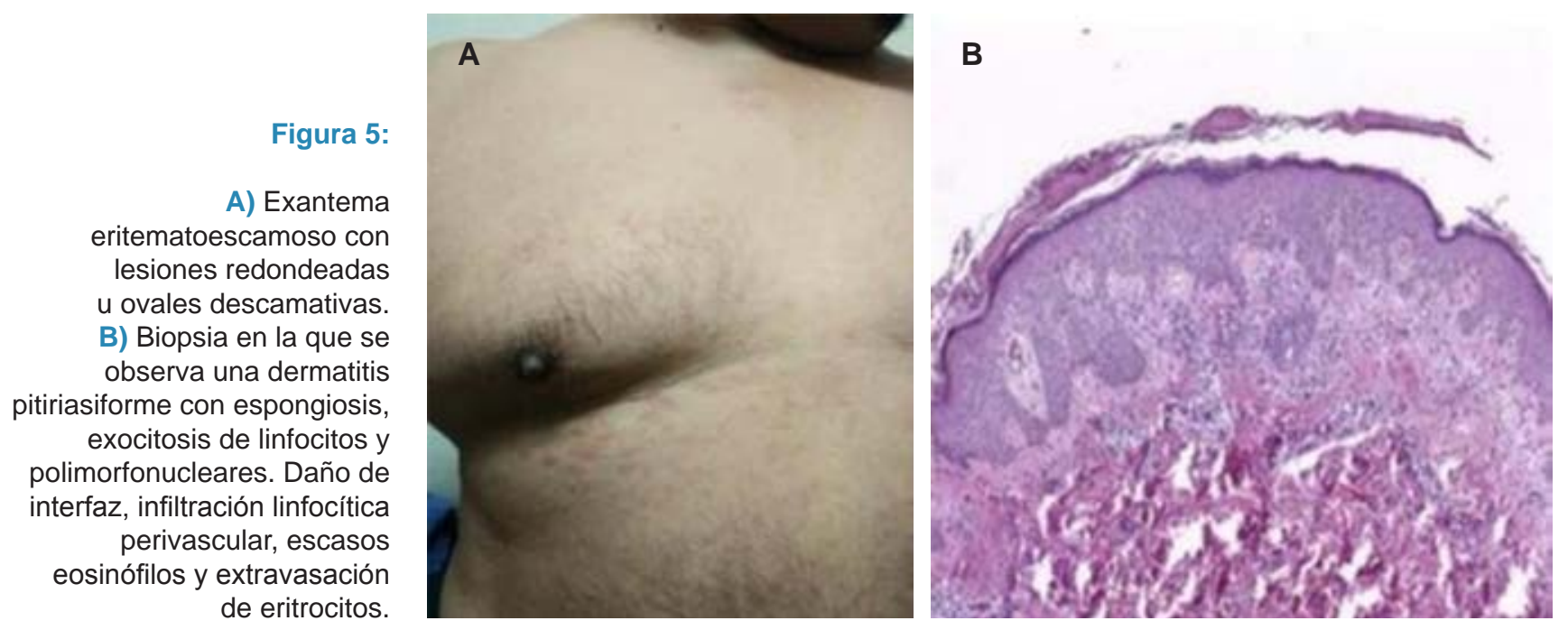

y lubricantes tópicos fue efectivo y siete días después la dermatosis remitió (Figura 4).

\section{Caso 5}

Paciente masculino de 47 años de edad. Apendicectomía a los 22 años. Obesidad desde los ocho años de edad, hipertensión arterial sistémica desde los 27 años de edad, tratado con amlodipino, losartán e hidroclorotiazida. Diabetes mellitus tipo II desde hace 10 años tratada con metformina $500 \mathrm{mg}$.

El 03 de septiembre se hace PCR para SARS-CoV-2, pues su esposa dio positivo en una prueba en su trabajo. El 17 de septiembre le reportan la prueba positiva, se encontraba asintomático hasta el día 18 del mismo mes cuando que aparece un exantema urticariforme que fue manejado por varios facultativos sin resultados. Una semana después se observa exantema maculopapular con elementos ovales y descamativos. Sin placa heraldo, pero morfología similar a la pitiriasis rosada. Se manejó con glucocorticoides tópicos y sistémicos (Figura 5).

\section{DISCUSIÓN}

Los exantemas similares a la pitiriasis rosada parecen estar asociados cada vez con más frecuencia a la infección por SARS-CoV-2. Histológicamente los hallazgos son similares en casi todos los exantemas causados por el virus. ${ }^{1-3}$

La biopsia de piel por lo regular muestra degeneración vacuolar de la capa basal con exocitosis de linfocitos. Se observa un infiltrado inflamatorio perivascular constituido por linfocitos y extravasación de eritrocitos. En nuestros casos hay uno que mostró positividad a la inmunohistoquímica con proteína Spike de SARS-CoV-2, aunque su PCR fue negativa.

El estudio de Drago y colaboradores ${ }^{1}$ menciona que el número de pacientes con pitiriasis rosada que acudieron a las clínicas dermatológicas se incrementó cinco veces en el mismo periodo del año pasado. Los hospitales no registraron ese incremento por circunstancias de la pandemia, ya que los enfermos no asistieron al hospital.

Se ha observado que en la literatura hay múltiples casos de pitiriasis rosada like. Lamentablemente casi ninguno pudo establecer la relación con la infección con herpes virus 6 y $7 .^{1}$ En nuestro país no contamos con la posibilidad de investigar este virus. No se había sospechado del El EBV en el momento en que atendimos los casos.

Los autores que lo pudieron investigar piensan que existe una relación entre el SARS-CoV-2 y la activación de los virus HHV 6 y 7 . Probablemente la linfopenia causada por el nuevo virus es lo que lo propicia. ${ }^{4} \mathrm{El}$ efecto del virus en el endotelio vascular y la tormenta inmunológica responsable del síndrome inflamatorio multisistémico por SARS-CoV-2 pueden causar también la reactivación de otros virus y explicar el aumento de las pitiriasis rosadas. ${ }^{5,6}$ Sin embargo, la PCR podría ser negativa según el tiempo que haya pasado entre el inicio de la enfermedad COVID-19 y la reactivación de los otros virus. Desconocemos por qué aproximadamente la mitad de los casos tienen pruebas negativas. Sin embargo los datos epidemiológicos sugieren que la dermatosis puede asociarse con la infección de SARS-CoV-2, pues la frecuencia se elevó 5 veces más que los años anteriores. Es posible que en estos casos una enfermedad COVID-19 puede reactivar otros virus, sobre todo de la familia de los herpesvirus. 


\section{REFERENCIAS}

1. Drago F, Ciccarese G, Rebora A, Parodi A. Human herpesvirus-6, -7 and Epstein Barr virus reactivation in pitiriasis rosea during COVID-19. J Med Virol. 2020; 93 (4): 1850-1851. doi: 10.1002/jmv.26549.

2. Ehsani $\mathbf{A H}$, Nasimi M, Bigdelo Z. Pityriasis rosea as a cutaneous manifestation of COVID-19 infection. J Eur Acad Dermatol Venereol. 2020; 34 (9): e436-e437. doi: 10.1111 / jdv.16579.

3. Galván CC, Català A, Carretero HG, Rodríguez-Jiménez P, Fernández ND, Rodríguez-Villa LA et al. Classification of the cutaneous manifestations of COVID-19: a rapid prospective nationwide consensus study in Spain with 375 cases. Br J Dermatol. 2020; 183 (1): 71-77.
4. Dursun R, Temiz SA. The clinics of HHV-6 infection in COVID-19 pandemic: Pityriasis rosea and Kawasaki disease. Dermatol Ther. 2020; 33 (4): e13730. doi: 10.1111/dth.13730.

5. Merhy R, Sarkis AS, Stephan F. Pityriasis rosea as a leading manifestation of COVID-19 infection. J Eur Acad Dermatol Venereol. 2021; 35 (4): e246-e247. Available in: 10.1111/jdv.17052. doi: $10.1111 / j d v .17052$.

6. Enguix DM, Salazar NMC, Romero MDT. Erupción tipo pitiriasis rosada de Gibert en una paciente asintomática con positividad para COVID-19. Med Clin (Barc). 2020;155 (6): 273.

Conflicto de intereses: Sin conflicto de intereses. 